Article

\title{
Multi-Objective Optimization of a Solar Chimney Power Plant with Inclined Collector Roof Using Genetic Algorithm
}

\author{
Ehsan Gholamalizadeh and Man-Hoe Kim * \\ School of Mechanical Engineering, Kyungpook National University, Daegu 41566, Korea; \\ gholamalizadeh@gmail.com \\ * Correspondence: manhoe.kim@knu.ac.kr; Tel.: +82-53-950-5576 \\ Academic Editor: Antonio Calvo Hernández \\ Received: 11 October 2016; Accepted: 17 November 2016; Published: 21 November 2016
}

\begin{abstract}
This paper presents an optimization of a solar chimney power plant with an inclined collector roof using genetic algorithms. Five design parameters that affect the system performance are the collector radius, collector inlet height, collector outlet height, chimney height and diameter. A multi-objective design to simultaneously optimize three conflicting objectives including system efficiency, power output and expenditure is used. Based on this approach, obtaining the best combination of the possible geometrical parameters, performance of two built pilot power plants in Kerman (Iran) and Manzanares (Spain) are optimized thermo-economically. The heights of the zero-slope collectors of the Kerman and Manzanares systems are $2 \mathrm{~m}$ and $1.85 \mathrm{~m}$, respectively. The results show that in the Kerman pilot the optimal collector inlet and outlet heights are $1.5 \mathrm{~m}$ and $2.95 \mathrm{~m}$, respectively, while those optimal heights in the Manzanares prototype are $1.5 \mathrm{~m}$ and $4.6 \mathrm{~m}$, respectively. It is found that selecting the optimal collector roof configuration in addition to the other design parameters has a significant effect in the system optimization process.
\end{abstract}

Keywords: solar chimney power plant; inclined collector roof; renewable energy; multi-objective genetic algorithm

\section{Introduction}

A Solar Chimney Power Plant (SCPP) is a kind of indirect solar thermal system. The SCPP consists of four simple components: a solar collector, a tower built in the center of the solar collector called chimney, energy storage media and a wind turbine. Figure 1 shows a schematic of the SCPP system. In this system, the ground surface is heated by utilizing thermal solar energy. Consequently, the air inside the collector is heated under a transparent collector roof due to convection from the ground and greenhouse effect. The airflow heated through the collector is lighter than the cold air inside the tower and hence, an upward buoyancy-driven flow is created through the chimney. Due to the suction from the chimney warmer, air is drawn from the solar collector and therefore ambient air enters the system from the collector inlet. Thus, upward buoyancy force inside the chimney creates a continuous updraft. Finally, the energy in the updraft runs a pressure-staged wind turbine installed at the chimney base and mechanical energy is converted into electricity using a generator [1]. 


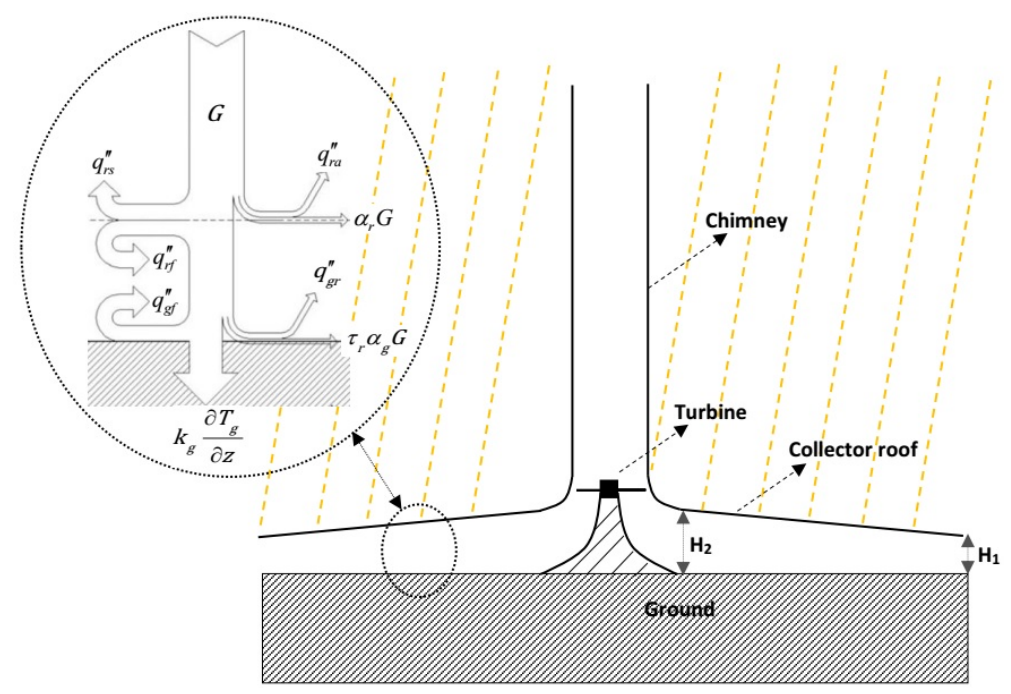

Figure 1. Schematic of an SCPP system.

In 1982, the first pilot SCPP was built in Manzanares, Spain. This system comprised a solar collector with a radius of $122 \mathrm{~m}$, and a chimney with a height and diameter of $194.6 \mathrm{~m}$ and $10 \mathrm{~m}$, respectively. The average height of the solar collector was $1.85 \mathrm{~m}$. This power plant was designed to produce a $50-\mathrm{kW}$ electrical power output. The principles for the solar chimney system were presented by Haaf et al. [2]. Then, for the first time, Haaf [3] published the preliminary test results of the Manzanares SCPP. Schlaich published a book on solar chimneys in 1995 [4]. Theoretical modeling and experimental data of a built SCPP were presented by Pasumarthi and Sherif [5]. Further, Padki and Sherif [6] and Gannon and von Backström [7] used simple mathematical models to predict the performance of the SCPP. An investigation on analytical and numerical models that consider the influence of ambient conditions and structural parameters on the power output was performed by Bernardes et al. [8]. Ming et al. [9] performed numerical analyses to study the effect of geometric variations on the performance of the Manzanares SCPP. Pretorius and Kröger [10] studied the convective heat transfer and momentum relations of an SCPP. Convective heat transfer coefficients in the collector, which were reported in the earlier investigations $[8,10]$, were compared in [11]. The feasibility of SCPP systems was considered by Nizetic et al. [12]. Pretorius and Kröger [13] presented an approximate thermo-economic model for optimizing an SCPP system. The main parts of the SCPP, including the collector, wind turbine, and chimney were modeled theoretically, and the equations were solved numerically by Koonsrisuk and Chitsomboon [14]. Gholamalizadeh and Mansouri [15] developed a comprehensive mathematical model to calculate the performance and total expenditure of an SCPP. Moreover, in several investigations, a coupled set of conservation equations of mass, momentum, and energy have been solved using computational fluid dynamics (CFD). Bernardes et al. [16] developed a steady-state Navier-Stokes solution and energy equations for the natural laminar convection using the finite volume method (FVM). A two-dimensional (2D) steady-state CFD simulation of the SCPP system was carried out by Pastohr et al. [17]. Koonsrisuk and Chitsomboon [18] solved the conservation equations of mass, momentum, and energy in an SCPP using the FVM. Chergui et al. [19] solved steady-state Navier-Stokes equations, as well as continuity and energy equations for a natural laminar convection in an axisymmetric system. Xu et al. [20] studied the effects of the solar irradiation and pressure drop across the turbine in an SCPP using steady-state numerical simulations. Koonsrisuk and Chitsomboon [21] used CFD to study the changes in the flow properties due to the variations in the flow area. Guo et al. [22] presented a comprehensive theoretical model to accurately predict the annual performance of the SCPP by considering the hourly variation of the solar irradiation. Okoye et al. [23] investigated the performance and feasibility of an SCPP for different values of the geometric parameters. Li et al. [24] developed an economic model to 
analyze the reinforced concrete SCPP. Patel et al. [25] carried out CFD simulations to study the effects of the constructural parameters on the performance of the SCPP to improve the flow characteristics of the system. Gholamalizadeh and Kim [26] considered the role of the greenhouse effect on the buoyancy-driven flow and heat transfer through the SCPP by employing an unsteady 3D turbulent model using CFD. Guo et al. [27] conducted a numerical approach considering the radiation model, solar load model, and the turbine.

The review of the literature indicates that only in a few investigations the effect of the inclination of the collector roof on the system performance has been studied. An appropriate design of the collector construction is one of the main factors to improve the performance of the SCPP. A multi-objective genetic algorithm optimization method was presented by Gholamalizadeh and Kim [28] for an SCPP system to simultaneously optimize the total efficiency, power output, and expenditure, obtaining optimal geometric parameters. This optimization investigation has been carried out to optimize the configuration of SCPP systems with a zero-slope collector roof. It is worth noting that an appropriate collector design results in the performance improvement of the system. One of the important parameters to be considered for design a collector is the inclination of the collector roof. A parametric study was performed using CFD to illustrate the effect of the inclined collector configuration on the convection pattern through the collector and also the SCPP performance while other construction parameters are fixed to the Manzanares prototype dimensions [29].

This study presents advancement to previously reported SCPP optimization [28] for two built SCPPs in Kerman and Manzanares. For this purpose, we focus on the performance optimization of the collector to examine the effect of the roof inclination of the collector on the performance of the SCPP systems. To thermo-economically optimize the system performance a multiple-objective design approach including system efficiency, power output and system expenditure is considered, using genetic algorithms. The selected design parameters are inlet and outlet height of the collector, collector radius, chimney height and diameter.

\section{Mathematical Modeling}

A numerical model is implemented to be applied through the optimization process based on Genetic Algorithms. A validated comprehensive mathematical modeling to design the SCPP was developed in [15]. This model is used to calculate the objective functions of the optimization process in this study. In this section, the model is briefly described.

Using continuity and energy conservation equations through the solar collector, the velocity and temperature distributions can be calculated by Equations (1) and (2), respectively.

$$
\begin{gathered}
v(r)=\frac{R_{\mathrm{c}}^{2} \rho_{r=0}}{r H_{\mathrm{coll}}(r) \rho(r)} \sqrt{\frac{g H_{\mathrm{c}}\left(T_{r=0}-T_{\mathrm{a}}\right)}{6 T_{\mathrm{a}}}} \\
\frac{d T}{d r}=\frac{2 r\left(q_{\mathrm{gf}}^{\prime \prime}+q_{\mathrm{rf}}^{\prime \prime}\right)}{\rho_{r=0} v_{r=0} R_{\mathrm{c}}^{2} C_{\mathrm{p}}}
\end{gathered}
$$

The equations of energy balance for the solar collector roof and ground are expressed by Equations (3) and (4), respectively.

$$
\begin{aligned}
& \alpha_{\mathrm{r}} G+q_{\mathrm{gr}}^{\prime \prime}+q_{\mathrm{gf}}^{\prime \prime}=q_{\mathrm{ra}}^{\prime \prime}+q_{\mathrm{rs}}^{\prime \prime}+q_{\mathrm{rf}}^{\prime \prime} \\
& \tau_{\mathrm{r}} \alpha_{\mathrm{g}} G=q_{\mathrm{gr}}^{\prime \prime}-\left.k_{\mathrm{g}} \frac{\partial T_{\mathrm{g}}}{\partial z}\right|_{z=0}+q_{\mathrm{gf}}^{\prime \prime}
\end{aligned}
$$

Conduction heat transfer in the ground is calculated as below:

$$
\frac{\partial^{2} T_{\mathrm{g}}}{\partial \mathrm{z}^{2}}=\frac{1}{\alpha} \frac{\partial T}{d t}
$$


where the boundary condition in the appropriate ground's depth can be expressed as a constant temperature boundary which is of the same value as ambient air temperature [15].

\subsection{Convection from Ground to Collector Air}

When the temperature of ground surface is greater than the airflow temperature through the collector, the ground surface can be approximated as a heated horizontal surface facing up. In this case, Burger's correlation is applicable to calculate the convective heat transfer coefficient between the ground surface and airflow through the collector [15] as given below:

$$
h=3.87+0.0022\left(v \rho C_{\mathrm{p}} / \operatorname{Pr}^{\frac{2}{3}}\right)
$$

Similarly, Equation (6) is applicable for calculation of the convective heat transfer coefficient from the collector roof to the ambient air.

\subsection{Convection from Roof to the Collector Air}

The airflow inside the collector is assumed as the flow between parallel plates and, therefore, the convective heat transfer coefficient from the collector roof to the airflow through the collector can be calculated by Gnielinski's equation [15]:

$$
h=\frac{(f / 8)(\operatorname{Re}-1000) \operatorname{Pr}}{1+12.7(f / 8)^{1 / 2}\left(\operatorname{Pr}^{2 / 3}-1\right)}\left(\frac{k}{d_{\mathrm{h}}}\right)
$$

The total efficiency of the system is defined by

$$
\eta_{\text {scpp }}=\eta_{\text {coll }} \times \eta_{\mathrm{c}} \times \eta_{\mathrm{t}} \times \eta_{\text {gen }}
$$

2.3. Chimney Efficiency

$$
\eta_{\mathrm{c}}=\frac{g \times H_{\mathrm{c}}}{c_{\mathrm{p}} \times T_{\mathrm{a}}}
$$

The collector efficiency is defined as a ratio of enthalpy increase through the collector to solar energy which enter the collector via the transparent roof, as follows:

$$
\eta_{\text {coll }}=\left(\frac{\rho_{r=0} \times v_{r=0} \times A_{\mathrm{c}} \times c_{\mathrm{p}} \times\left(T_{r=0}-T_{\mathrm{a}}\right)}{G \times A_{\text {coll }}}\right)
$$

The efficiency of the axial wind turbine is calculated as

$$
\eta_{\mathrm{t}}=\frac{P_{\mathrm{cl}}-P_{\mathrm{tc}}}{P_{\mathrm{tc}}}=1-\frac{v_{r=0}^{2}}{2 \times c_{\mathrm{p}} \times \eta_{\mathrm{c}} \times\left(T_{r=0}-T_{a}\right)}
$$

2.4. Total System Expenditure $\left(E_{\text {scpp }}\right)$

$$
E_{\text {scpp }}=\left(\left[(\pi / 4) \times \mathrm{H}_{\mathrm{c}}\left(\left(d_{\mathrm{c}}+0.001 H_{\mathrm{c}}\right)^{2}-d_{\mathrm{c}}^{2}\right)\right]+\left[A_{\text {coll }}(p t)_{\text {coll }} E_{\mathrm{c}}\left(1+(p t)_{H_{\text {coll }}} H_{\text {coll }}\right)\right]\right)
$$

2.5. The Power Output $\left(P_{\text {scpp }}\right)$

$$
P_{\text {scpp }}=\eta_{\text {scpp }} \times G \times A_{\text {coll }}
$$




\subsection{Genetic Algorithm}

In the area of evolutionary computation, such optimization algorithms simulate an evolutionary process where the goal is to evolve solutions by means of crossover, mutation, and selection based on their quality (fitness) with respect to the optimization problem at hand [30]. Genetic algorithms are optimization techniques based on natural genetics. Firstly, a set of points in the optimization space is randomly generated and is then transformed into a new one. The new set will contain more points that are nearer to the global optimum. This procedure is continuously repeated until a predefined stopping criterion, usually a maximum number of generations, is satisfied. One of the advantages of the Genetic algorithms is to find several equivalently optimal points in the optimization space. The fundamental of the Genetic algorithms is described in detail in [30].

The multi-objective genetic algorithm function called "gamultiobj" is employed via the MATLAB global optimization toolbox [31] to optimize the SCPP configuration. A controlled elitist genetic algorithm (variant of the nondominated sorting genetic algorithm (NSGA-II) is used in the gamultiobj function [32].

\section{Results and Discussion}

The air velocity at the chimney base and the temperature rise $(\Delta \mathrm{T})$ through the collector of the Manzanares SCPP were reported as $8.8 \mathrm{~m} / \mathrm{s}$ and $17.5 \mathrm{~K}$, respectively, in the solar irradiation of $850 \mathrm{~W} / \mathrm{m}^{2}$ [3], while the values for the numerical model are about $9 \mathrm{~m} / \mathrm{s}$ and $18 \mathrm{~K}$. The power output of $40 \mathrm{~kW}$ was obtained from the measured midday $\Delta \mathrm{T}$ of 17.5 [3], which is in a close agreement with the numerically predicted value of about $41 \mathrm{~kW}$.

To thermo-economically optimize the performance of the SCCP with an inclined collector roof a triple-objective optimization design is employed using genetic algorithms. The system efficiency, the power output and the expenditure are considered as the objective functions. As mentioned before, one of the advantages of the Genetic algorithms is to find several equivalently optimal points in the optimization space. It causes the designer can select the most applicable solution to optimize the problem. For this purpose, all the parameters that affect the performance of the collector must be simultaneously changed. The design parameters are selected as: inlet and outlet height of the collector, collector radius, chimney height and diameter. The optimum value of the design parameters is obtained when both the system efficiency and power output are maximized, while expenditure of the system is minimized.

\subsection{Kerman SCPP Optimization}

The Kerman SCPP has a solar collector with a radius of $20 \mathrm{~m}$, and a chimney with a height and diameter of $60 \mathrm{~m}$ and $3 \mathrm{~m}$, respectively. The average height of the solar collector was $2 \mathrm{~m}$. The range of variation of design variables bounded by the structurally feasible values for Kerman power plant is listed in Table 1.

Table 1. Design parameters for Kerman power plant and their acceptable ranges.

\begin{tabular}{ccc}
\hline Design parameters & Kerman SCPP & Range \\
\hline Collector radius $(\mathrm{m})$ & 20 & $15-100$ \\
Collector inlet height $(\mathrm{m})$ & 2 & $0.5-3$ \\
Collector outlet height $(\mathrm{m})$ & 2 & $0.5-3\left(\mathrm{H}_{2}>\mathrm{H}_{1}\right)$ \\
Chimney height $(\mathrm{m})$ & 60 & $60-105$ \\
Chimney diameter $(\mathrm{m})$ & 3 & $3-5$ \\
\hline
\end{tabular}

The final calculated three-dimensional (3-D) Pareto front for the Kerman power plant is shown in Figure 2. Thirty different non-inferior optimal configurations were found. Figures $3 a, b$ and 4 show corresponding 2-D solutions of the Pareto front. The tradeoff between the total efficiency and the 
power output for the Kerman SCPP is illustrated in Figure 3a. Correspondingly, Figure 3b shows the tradeoff between the total efficiency and the expenditure. The total efficiency of the Kerman SCPP with the existing configuration is estimated about $6.569 \times 10^{-4}$. Figure $3 \mathrm{~b}$ shows that, compared to the existing Kerman SCPP, the total efficiency of the majority of optimal points are relatively higher, however, the total efficiency still remains low.

Figure 4 presents the tradeoff between the power output and the expenditure. There is a wide range of performance and expenditure in the optimal configurations, none of which has priority over the others from a thermo-economical point of view. Hence, a designer is able to choose an optimum configuration among the optimal solutions. The ratio of the power output to the expenditure $\left(\mathrm{RPE}=P_{\mathrm{scpp}} / E_{\mathrm{scpp}}\right)$ for all optimal configurations is shown in Figure 5. Comparing the obtained Pareto set, optimal configuration for the Kerman SCPP is selected and reported in Table 2. The optimal configuration of the Kerman SCPP with the inclined collector roof has a chimney with the height and diameter of 103.26 and $4.94 \mathrm{~m}$, respectively, and the radius of its solar collector is $79.32 \mathrm{~m}$. In addition, Table 2 presents the performance and expenditure of the selected optimal point for the SCPP with the inclined collector roof in detail and compares them to the values of the Kerman SCPP with a zero-slope roof. Compared to optimal configuration of the Kerman SCPP with a zero-slope roof, the total efficiency, power output and expenditure of the optimal configuration are 1.047, 1.158 and 1.050 times greater, respectively.

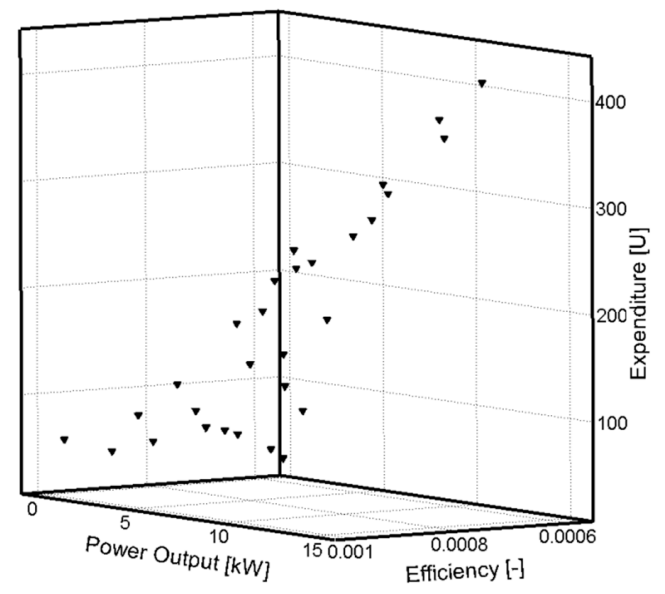

Figure 2. The Pareto front of the Kerman power plant.

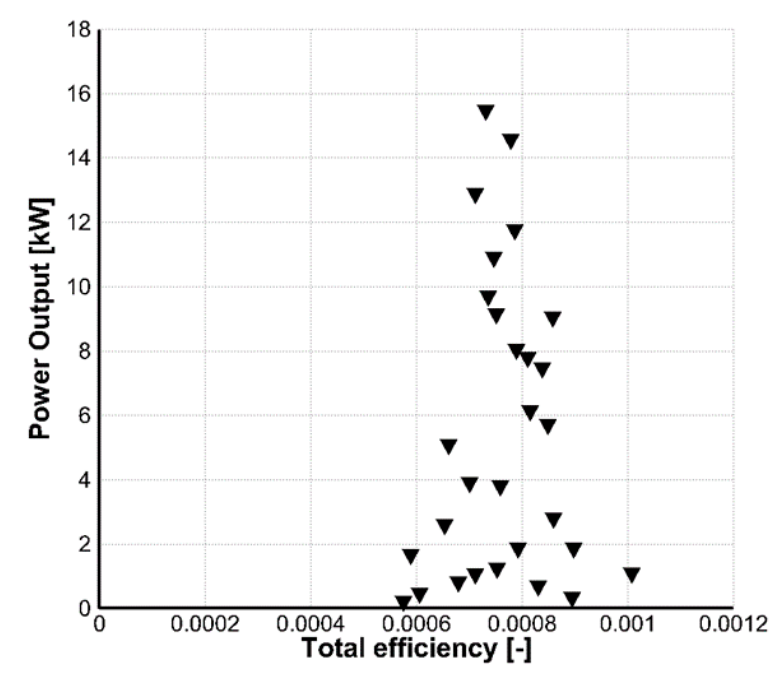

(a)

Figure 3. Cont. 


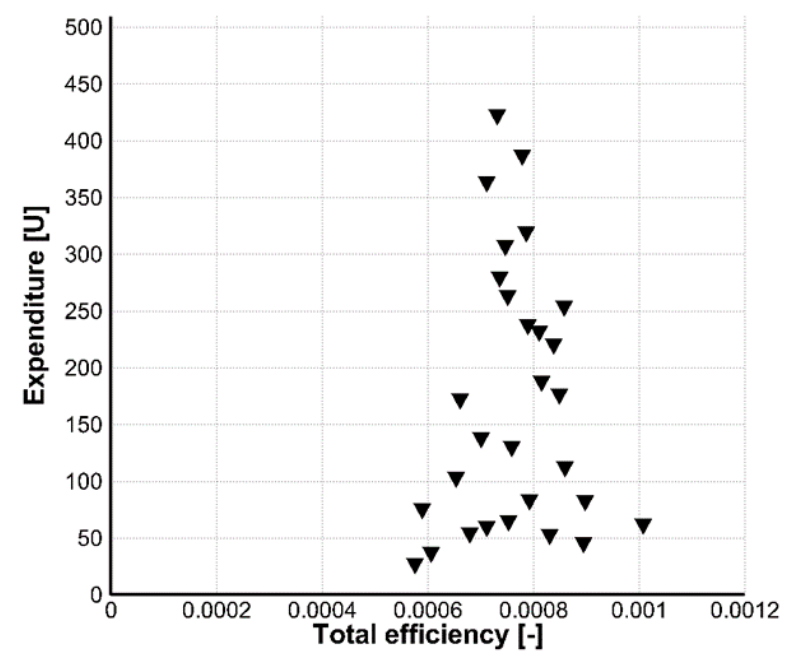

(b)

Figure 3. (a) Tradeoff between the power output and total efficiency for the Kerman SCPP; and (b) tradeoff between the total efficiency and the expenditure for the Kerman SCPP.

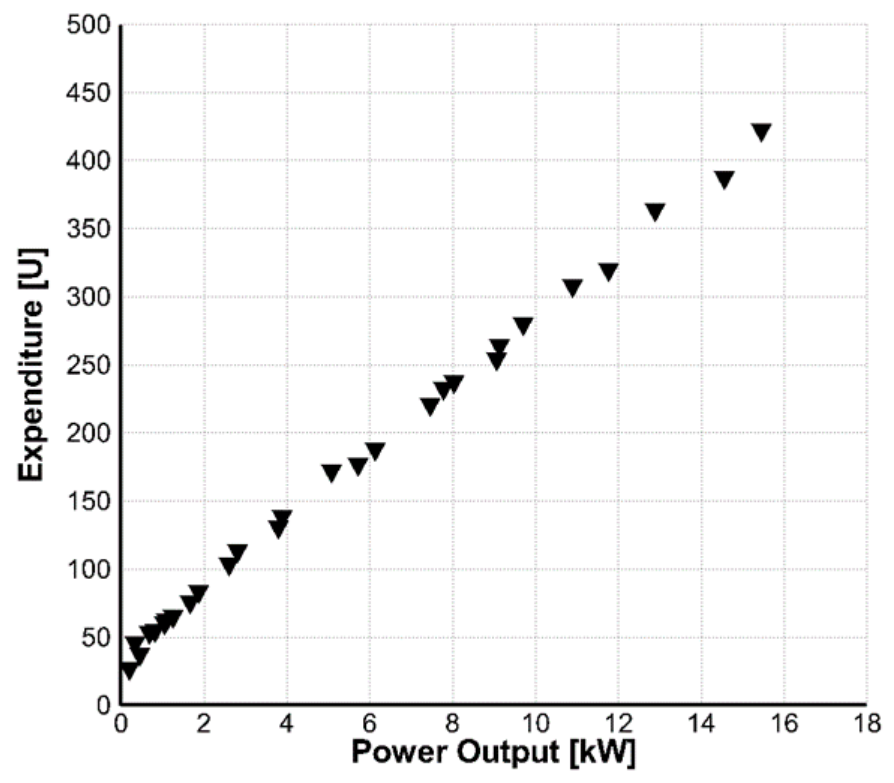

Figure 4. Tradeoff between the expenditure and power output for the Kerman SCPP.

Table 2. Comparison of the design parameters and objective functions between selected solutions of the Pareto set and Kerman power plant.

\begin{tabular}{lcc}
\hline \multicolumn{1}{c}{ Design parameters } & $\begin{array}{c}\text { Optimal Solution for } \\
\text { Zero-Slope Roof }\end{array}$ & $\begin{array}{c}\text { Optimal Solution for } \\
\text { Inclined Roof }\end{array}$ \\
\hline Collector radius $(\mathrm{m})$ & 75.5 & 79.32 \\
Collector inlet height $(\mathrm{m})$ & 2 & 1.5 \\
Collector outlet height $(\mathrm{m})$ & 2 & 2.95 \\
Chimney height $(\mathrm{m})$ & 104.6 & 103.26 \\
Chimney diameter $(\mathrm{m})$ & 4.90 & 4.94 \\
Total efficiency & $7.51 \times 10^{-4}$ & $7.86 \times 10^{-4}$ \\
Power output $(\mathrm{kW})$ & 10.1 & 11.7 \\
Expenditure $(\mathrm{U})$ & 304.50 & 319.77 \\
RPE $(\mathrm{kW} / \mathrm{U})$ & 0.0332 & 0.0366 \\
\hline
\end{tabular}




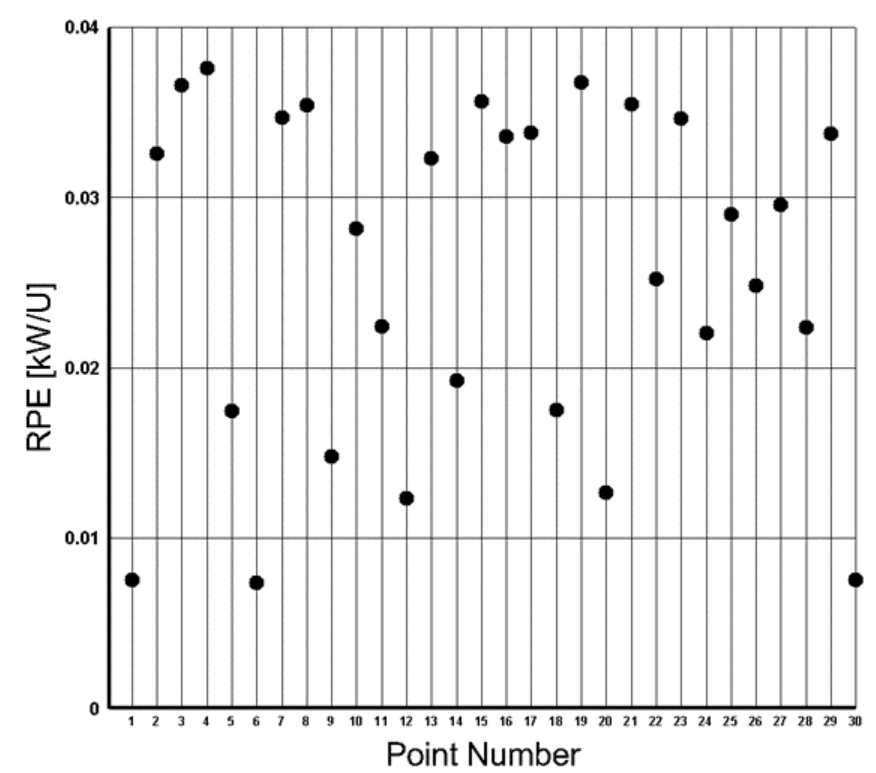

Figure 5. RPE for the optimal configurations of the Kerman power plant.

\subsection{Manzanares SCPP Optimization}

In this section, calculations to optimize Manzanares SCPP with the inclined collector roof have been performed. The range of variation of design variables selected for the Manzanares power plant is listed in Table 3. Figure 6 shows the final calculated 3-D Pareto front of solutions for the Manzanares power plant. Forty-two different non-inferior optimal configurations were found. Figures $7 \mathrm{a}, \mathrm{b}$ and 8 show corresponding 2-D solutions of the Pareto front.

Figure 7a illustrates the tradeoff between the total efficiency and the power output for the Manzanares prototype. Moreover, the tradeoff between the total efficiency and the expenditure is shown in Figure $7 \mathrm{~b}$. The total efficiency of the Manzanares prototype with the existing configuration is about 0.0015. It is seen from the Pareto front that there is a relatively considerable improvement in the total efficiency at the optimal points. Correspondingly, the RPE values for all optimal configurations are shown in Figure 9. Comparing the obtained Pareto set, optimal configurations for the Manzanares SCPP is selected and reported in Table 4. The optimal configuration has a chimney with the height and diameter of 248.1 and $14.92 \mathrm{~m}$, respectively, and the radius of its solar collector is $174.3 \mathrm{~m}$. For this optimal configuration, the inlet and outlet collector heights are predicted 1.5 and $4.6 \mathrm{~m}$, respectively. In addition, in comparison to the optimal configuration of the Manzanares SCPP with zero-slope roof, the total efficiency and power output are 1.59 and 1.27 times greater, respectively, while expenditure is 1.06 less than the values of the optimal zero-slope roof configuration. It can be noted that the total efficiency in the both Kerman pilot and Manzanares prototype SCPP systems is low. The main reason is that the chimney efficiency is significantly low. It is found from Equation (8) that the total efficiency is influenced by the efficiency of the chimney. According to Equation (9), among all the design parameters, the chimney efficiency is only a function of the chimney height. Therefore, to increase the chimney efficiency, a chimney with a far bigger height is needed which is not suitable for such small-scale pilot systems. Consequently, in the small-scale solar chimney systems although the total efficiency is low, but optimizing the design parameters has a major role to increase the performance of the system thermo-economically. 
Table 3. Design parameters for Manzanares power plant and their acceptable ranges.

\begin{tabular}{ccc}
\hline Design parameters & Manzanares SCPP & Range \\
\hline Collector radius $(\mathrm{m})$ & 122 & $122-200$ \\
Collector inlet height $(\mathrm{m})$ & 1.85 & $0.5-5$ \\
Collector outlet height $(\mathrm{m})$ & 1.85 & $0.5-5\left(\mathrm{H}_{2}>\mathrm{H}_{1}\right)$ \\
Chimney height $(\mathrm{m})$ & 194.6 & $194.6-250$ \\
Chimney diameter $(\mathrm{m})$ & 10 & $10-15$ \\
\hline
\end{tabular}

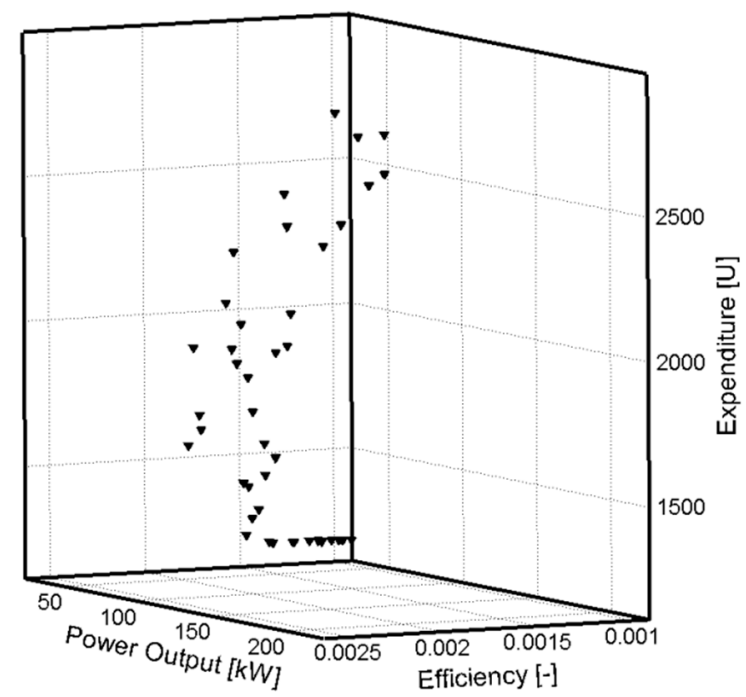

Figure 6. The Pareto front of the Manzanares power plant.

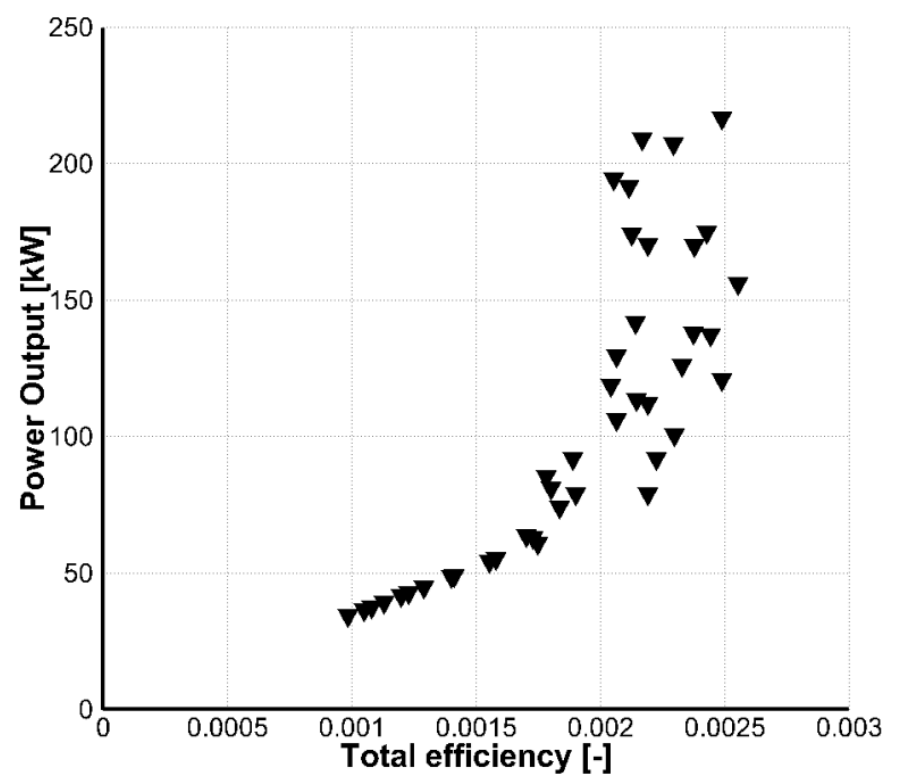

(a)

Figure 7. Cont. 


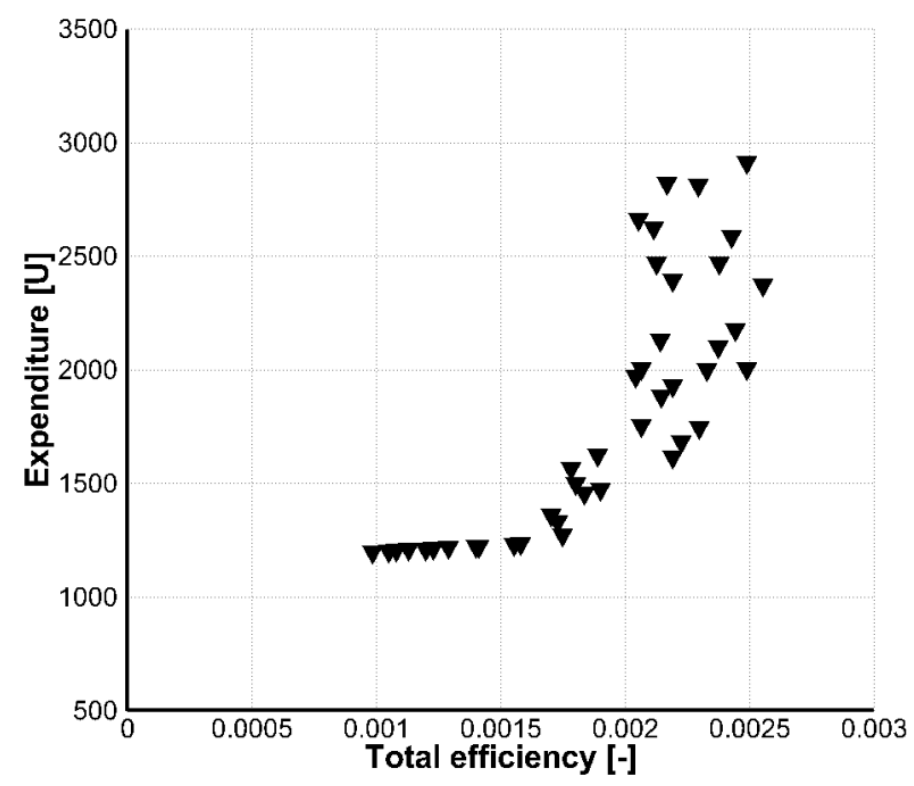

(b)

Figure 7. (a) Tradeoff between power output and total efficiency for the Manzanares SCPP; and (b) Tradeoff between total efficiency and expenditure for the Manzanares SCPP.

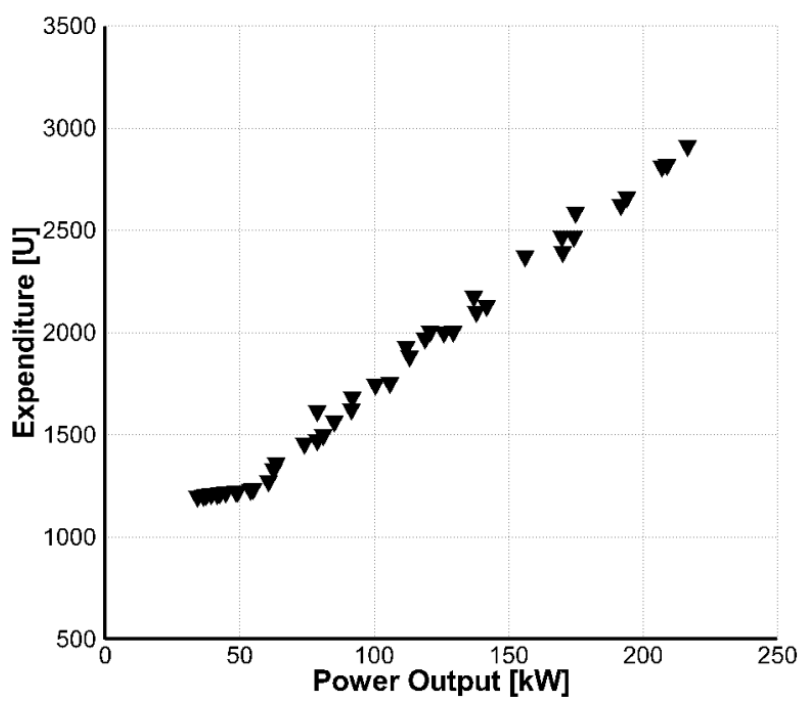

Figure 8. Tradeoff between the expenditure and power output for the Manzanares SCPP.

Table 4. Comparison of the design parameters and objective functions between selected solutions of the Pareto set and Manzanares power plant.

\begin{tabular}{lcc}
\hline \multicolumn{1}{c}{ Design Parameters } & $\begin{array}{c}\text { Optimal Solution for } \\
\text { Zero-Slope Roof }\end{array}$ & $\begin{array}{c}\text { Optimal Solution for } \\
\text { Inclined Roof }\end{array}$ \\
\hline Collector radius $(\mathrm{m})$ & 193.84 & 174.3 \\
Collector inlet height $(\mathrm{m})$ & 1.85 & 1.5 \\
Collector outlet height $(\mathrm{m})$ & 1.85 & 4.6 \\
Chimney height $(\mathrm{m})$ & 247.88 & 248.1 \\
Chimney diameter $(\mathrm{m})$ & 14.79 & 14.92 \\
Total efficiency & $1.527 \times 10^{-3}$ & $2.43 \times 10^{-3}$ \\
Power output $(\mathrm{kW})$ & 137 & 175 \\
Expenditure $(\mathrm{U})$ & 2953 & 2786 \\
RPE $(\mathrm{kW} / \mathrm{U})$ & 0.0464 & 0.0628 \\
\hline
\end{tabular}




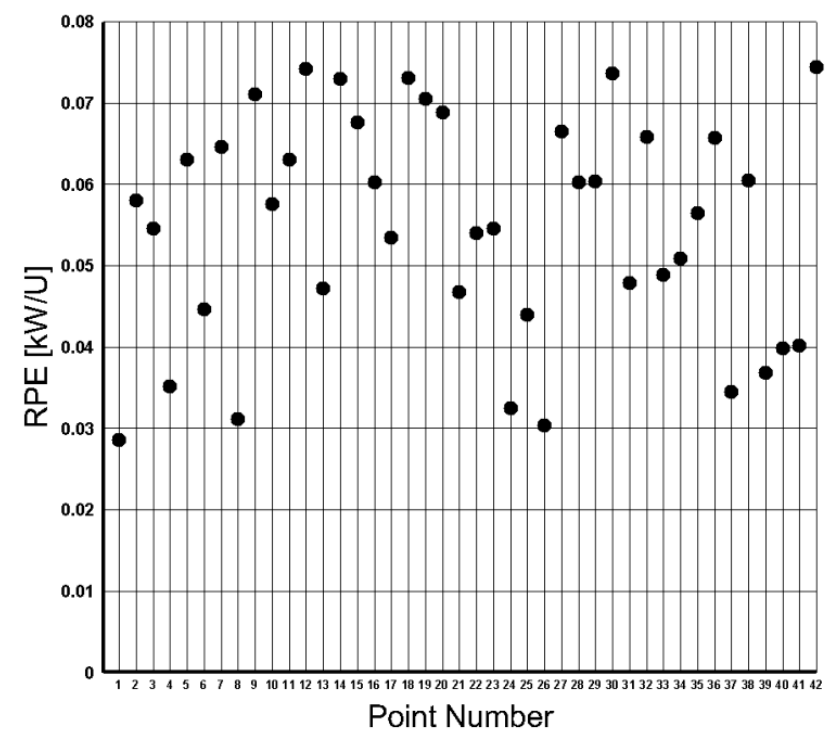

Figure 9. RPE for the optimal configurations of the Manzanares power plant.

\section{Conclusions}

This study presents advancement to previous investigations to optimize a solar chimney power plant system by considering an inclined collector roof. For this purpose, to optimize the performance of the SCPP a three-objective design was applied. To thermo-economically optimize the system, a multi-objective genetic algorithm was employed. To obtain the best combination of design parameters (collector radius, collector roof inclination, collector inlet height, chimney height and chimney diameter), the total efficiency, the power output and the expenditure were simultaneously optimized. As demonstrative examples, the performance optimization of the system with the inclined collector roof for two built pilot SCPPs in Kerman and Manzanares were considered. Results reveal the importance of optimizing the design parameters on the system performance improvement. It is found that, in addition to the design parameters for a system with the zero-slope collector including the collector radius, and height and diameter of the chimney, optimizing the collector roof inclination and collector inlet height helps to improve the performance of the system. In addition, although a slight improvement in the total efficiency of the optimal results is predicted, there is a relatively considerable increase in the power output. It is concluded that the optimization process presented in this study helps design an SCPP system with an inclined collector with an optimum performance and expenditure.

Acknowledgments: This research was supported by the Engineering Development Research Center (Grant No. 10000990) by the Ministry of Trade, Industry \& Energy, Korea.

Author Contributions: Ehsan Gholamalizadeh did the optimization modeling and drafted the manuscript. Man-Hoe Kim supervised the research and edited the manuscript. Authors read and approved the manuscript.

Conflicts of Interest: The authors declare no conflict of interest.

\section{Nomenclature}

A

$c_{\mathrm{p}}$

$d$

$d_{\mathrm{h}}$

E

$f$ area $\left(\mathrm{m}^{2}\right)$

specific heat capacity $(\mathrm{J} / \mathrm{kg} \mathrm{K})$

diameter $(\mathrm{m})$

hydraulic diameter of collector (m)

Expenditure (U)

Darcy friction factor 


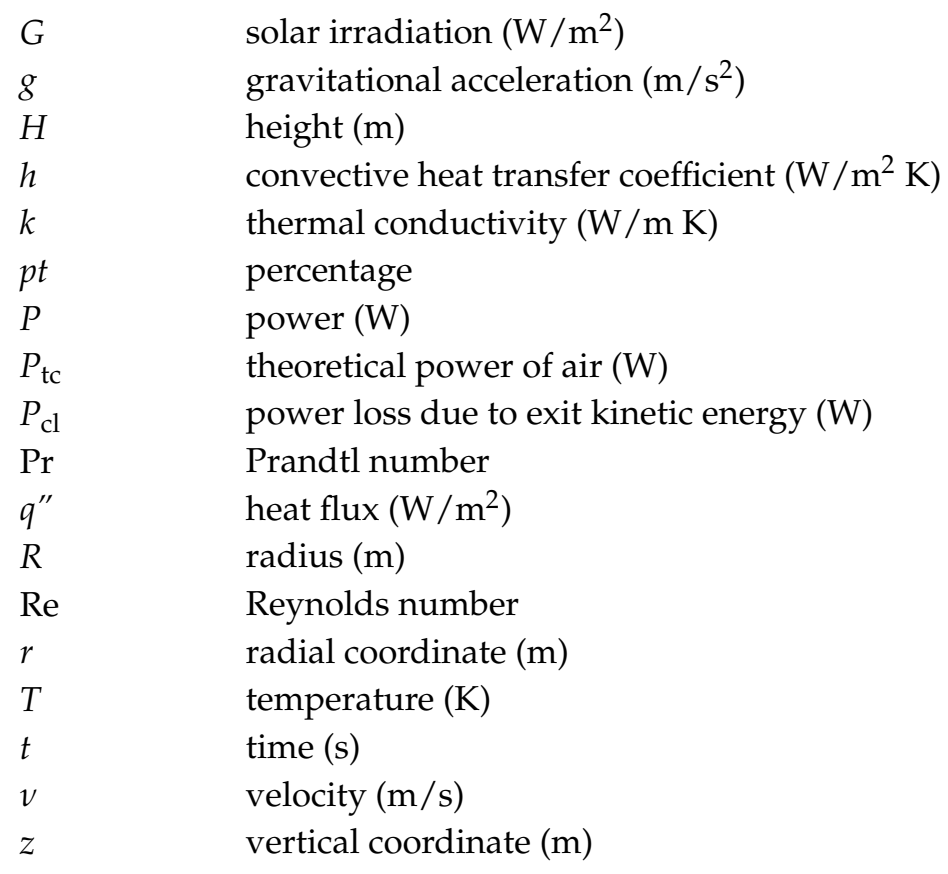

\section{Greek Symbols}

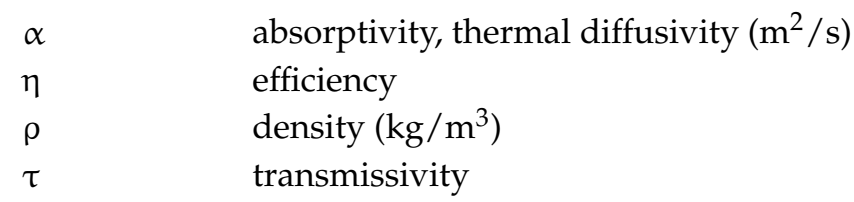

\section{Subscripts}

$\begin{array}{ll}\text { a } & \text { ambient air } \\ \text { c } & \text { chimney } \\ \text { coll } & \text { collector } \\ \mathrm{g} & \text { ground } \\ \text { gen } & \text { generator } \\ \text { gf } & \text { ground to fluid flow } \\ \text { gr } & \text { ground to collector roof } \\ \mathrm{r} & \text { collector roof } \\ \text { ra } & \text { collector roof to ambient air } \\ \text { rf } & \text { collector roof to fluid flow } \\ \text { rs } & \text { collector roof to sky } \\ \text { SCPP } & \text { solar chimney power plant } \\ \mathrm{t} & \text { turbine }\end{array}$

\section{References}

1. Schlaich, J.; Bergermann, R.; Schiel, W.; Weinrebe, G. Design of Commercial Solar Updraft Tower Systems-Utilization of Solar Induced Convective Flows for Power Generation. J. Sol. Energy Eng. 2005, 127, 117-124. [CrossRef]

2. Haaf, W.; Friedrich, K.; Mayr, G.; Schlaich, J. Solar Chimneys Part I: Principle and Construction of the Pilot Plant in Manzanares. Int. J. Sol. Energy 1983, 2, 3-20. [CrossRef]

3. Haaf, W. Solar Chimneys: Part II: Preliminary Test Results from the Manzanares Pilot Plant. Int. J. Sol. Energy 1984, 2, 141-161. [CrossRef] 
4. Schlaich, J. The Solar Chimney: Electricity from the Sun; Edition Axel Menges: Stuttgart, Germany, 1995.

5. Pasumarthi, N.; Sherif, S.A. Experimental and theoretical performance of a demonstration solar chimney model-Part I: Mathematical model development. Int. J. Energy Res. 1998, 22, 277-288. [CrossRef]

6. Padki, M.M.; Sherif, S.A. On a simple analytical model for solar chimneys. Int. J. Energy Res. 1999, 23, 345-349. [CrossRef]

7. Gannon, A.J.; Backström, T.W.V. Solar Chimney Cycle Analysis with System Loss and Solar Collector Performance. J. Sol. Energy Eng. 2000, 122, 133-137. [CrossRef]

8. Bernardes, M.A.S.; Voß, A.; Weinrebe, G. Thermal and technical analyses of solar chimneys. Sol. Energy 2003, 75, 511-524. [CrossRef]

9. Tingzhen, M.; Wei, L.; Guoliang, X. Analytical and numerical investigation of the solar chimney power plant systems. Int. J. Energy Res. 2006, 30, 861-873. [CrossRef]

10. Pretorius, J.P.; Kröger, D.G. Solar Chimney Power Plant Performance. J. Sol. Energy Eng. 2006, 128, $302-311$. [CrossRef]

11. Bernardes, M.A.S.; Backström, T.W.V.; Kröger, D.G. Analysis of some available heat transfer coefficients applicable to solar chimney power plant collectors. Sol. Energy 2009, 83, 264-275. [CrossRef]

12. Nizetic, S.; Ninic, N.; Klarin, B. Analysis and feasibility of implementing solar chimney power plants in the Mediterranean region. Energy 2008, 33, 1680-1690. [CrossRef]

13. Pretorius, J.P.; Kröger, D.G. Thermoeconomic Optimization of a Solar Chimney Power Plant. J. Sol. Energy Eng. 2008, 130, 021015. [CrossRef]

14. Koonsrisuk, A.; Chitsomboon, T. Mathematical modeling of solar chimney power plants. Energy 2013, 51, 314-322. [CrossRef]

15. Gholamalizadeh, E.; Mansouri, S.H. A comprehensive approach to design and improve a solar chimney power plant: A special case-Kerman project. Appl. Energy 2013, 102, 975-982. [CrossRef]

16. Bernardes, M.A.S.; Valle, R.M.; Cortez, M.F.-B. Numerical analysis of natural laminar convection in a radial solar heater. Int. J. Therm. Sci. 1999, 38, 42-50. [CrossRef]

17. Pastohr, H.; Kornadt, O.; Gürlebeck, K. Numerical and analytical calculations of the temperature and flow field in the upwind power plant. Int. J. Energy Res. 2004, 28, 495-510. [CrossRef]

18. Koonsrisuk, A.; Chitsomboon, T. Dynamic similarity in solar chimney modeling. Sol. Energy 2007, 81, 1439-1446. [CrossRef]

19. Chergui, T.; Larbi, S.; Bouhdjar, A. Thermo-hydrodynamic aspect analysis of flows in solar chimney power plants-A case study. Renew. Sustain. Energy Rev. 2010, 14, 1410-1418. [CrossRef]

20. Xu, G.; Ming, T.; Pan, Y.; Meng, F.; Zhou, C. Numerical analysis on the performance of solar chimney power plant system. Energy Convers. Manag. 2011, 52, 876-883. [CrossRef]

21. Koonsrisuk, A.; Chitsomboon, T. Effects of flow area changes on the potential of solar chimney power plants. Energy 2013, 51, 400-406. [CrossRef]

22. Guo, P.-H.; Li, J.-Y.; Wang, Y. Annual performance analysis of the solar chimney power plant in Sinkiang, China. Energy Convers. Manag. 2014, 87, 392-399. [CrossRef]

23. Okoye, C.O.; Atikol, U. A parametric study on the feasibility of solar chimney power plants in North Cyprus conditions. Energy Convers. Manag. 2014, 80, 178-187. [CrossRef]

24. Li, W.; Wei, P.; Zhou, X. A cost-benefit analysis of power generation from commercial reinforced concrete solar chimney power plant. Energy Convers. Manag. 2014, 79, 104-113. [CrossRef]

25. Patel, S.K.; Prasad, D.; Ahmed, M.R. Computational studies on the effect of geometric parameters on the performance of a solar chimney power plant. Energy Convers. Manag. 2014, 77, 424-431. [CrossRef]

26. Gholamalizadeh, E.; Kim, M.-H. Three-dimensional CFD analysis for simulating the greenhouse effect in solar chimney power plants using a two-band radiation model. Renew. Energy 2014, 63, 498-506. [CrossRef]

27. Guo, P.-H.; Li, J.-Y.; Wang, Y. Numerical simulations of solar chimney power plant with radiation model. Renew. Energy 2014, 62, 24-30. [CrossRef]

28. Gholamalizadeh, E.; Kim, M.-H. Thermo-economic triple-objective optimization of a solar chimney power plant using genetic algorithms. Energy 2014, 70, 204-211. [CrossRef]

29. Gholamalizadeh, E.; Kim, M.-H. CFD (computational fluid dynamics) analysis of a solar-chimney power plant with inclined collector roof. Energy 2016, 107, 661-667. [CrossRef]

30. Panahi, M.S. A Computational Approach to Conceptual Design of Mechanical Systems. Ph.D. Thesis, University of Alberta, Edmonton, AB, Canada, January 1995. 
31. Chipperfield, A.; Fleming, P.; Pohlheim, H.; Fonseca, C. Genetic Algorithm Toolbox for Use with MATLAB. Available online: http://www.pohlheim.com/Papers/tr_gatbx12/ChipperfieldFlemingPohlheimFonseca_ tr_GATbx_v12.pdf (accessed on 17 November 2016).

32. Deb, K. Multi-Objective Optimization Using Evolutionary Algorithms; John Wiley \& Sons: Chichester, UK, 2001.

(c) 2016 by the authors; licensee MDPI, Basel, Switzerland. This article is an open access article distributed under the terms and conditions of the Creative Commons Attribution (CC-BY) license (http://creativecommons.org/licenses/by/4.0/). 